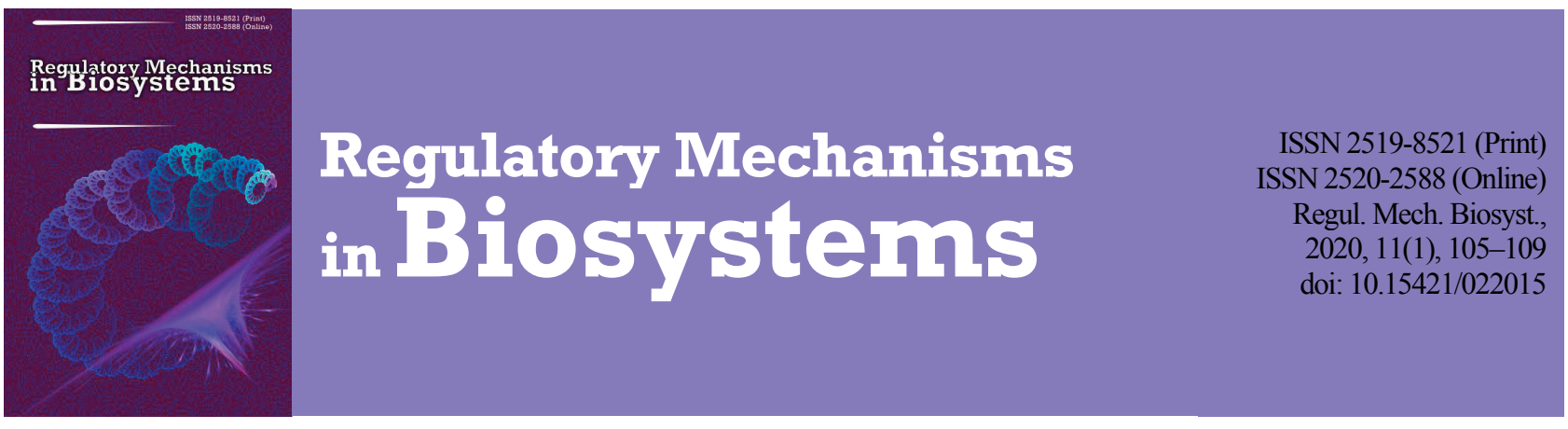

\title{
Antibacterial and fungicidal effect of ethanol extracts from Juniperus sabina, Chamaecyparis lawsoniana, Pseudotsuga menziesii and Cephalotaxus harringtonia
}

\author{
V. V. Zazharskyi*, P. O. Davydenko*, O. M. Kulishenko*, I. V. Borovik*, A. M. Kabar**, V. V. Brygadyrenko** \\ *Dnipro State Agrarian and Economic University, Dnipro, Ukraine \\ **Oles Honchar Dnipro National University, Dnipro, Ukraine
}

Article info

Received 16.01.2020

Received in revised form

Accepted 15.02.2020

Dnipro State Agrarian and

Economic University,

Sergiy Efremov st., 25,

Dnipro, 49000, Ukraine.

Tel.: +38-056-713-51-74.

E-mail:zazharskiy»@gmail.com

Oles Honchar Dnipro

National University

Gagarin av., 72,

Dnipro, 49010, Ukraine.

Tel.: +38-050-93-90-788

E-mail:brigad@ua.fm
Zazharskyi, V. V., Davydenko, P. O., Kulishenko, O. M., Borovik, I. V., Kabar, A. M., \& Brygadyrenko, V. V. (2020). Antibacterial and fungicidal effect of ethanol extracts from Juniperus sabina, Chamaecyparis lawsoniana, Pseudotsuga menziesii and Cephalotaxus harringtonia. Regulatory Mechanisms in Biosystems, 11(1), 105-109. doi:10.15421/022015

We determined a high antibacterial effect of ethanol extracts of four species of gymnosperms (Juniperus sabina, Chamaecyparis lawsoniana, Pseudotsuga menziesii and Cephalotaxus harringtonia) against 23 strains of bacteria of families Enterobacteriaceae (Escherichia coli, Enterococcus faecalis, Salmonella typhimurium, S. adobraco, Proteus vulgaris, P. mirabilis, Serratia marcescens, Klebsiella pneumoniae), Staphylococcaceae (Staphylococcus aureus, S. epidermidis), Yersiniaceae (Yersinia enterocolitica), Bacillaceae (Bacillus subtilis, B. cereus), Listeriaceae (Listeria ivanovi, L. innocua, L. monocytogenes), Corynebacteriaceae (Corynebacterium xerosis), Campylobacteraceae (Campylobacter jejuni), Nocardiaceae (Rhodococcus equi), Pseudomonadaceae (Pseudomonas aeruginosa) and one strain of fungi of the Saccharomycetaceae family (Candida albicans). The experiment in vitro revealed zone of inhibition of growth of colonies, measuring over $8 \mathrm{~mm}$, produced by ethanol extracts from J. sabina against seven species of bacteria (S. aureus, B. subtilis, B. cereus, L. innocua, C. xerosis, Rh. equi and $P$. aeruginosa), Ch. lawsoniana - against five species (E. coli, B. subtilis, L. innocua and Rh. equi), P. menziesii -two species (Rh. equi and P. mirabilis), C. harringtonia - ten species of microorganisms (E. coli, S. aureus, S. epidermidis, L. ivanovi, L. monocytogenes, $C$. xerosis, $C$. jejuni, $P$. vulgaris, $S$. marcescens and $C$. albicans). As a result of the research, the most promising plants for further in vivo study of antibacterial activity were C. harringtonia and J. sabina.

Keywords: growth inhibition zone; bacterial colonies; multi-resistant strains; gymnosperms; candidiasis.
Introduction

Over recent years, due to spread of antibiotic-polyresistant strains of bacteria which are poorly susceptible to treatment, more and more often reports emerge, describing the potential of the search for efficient antibacterial substances in ethanol plant extracts (Boyko et al., 2016; Zazharskyi et al., 2019a, b; Palchykov et al., 2019, 2020). Potentially, a subject of significant interest in this aspect is various groups of gymnosperms used for the greening of settlements.

Cephalotaxus harringtonii (Forbes) K. Kokh known as Japanese plum-yaw is an evergreen coniferous shrub or small tree from the Taxaceae family. Scioheliophyte, eutrophic, mesohyte. Quite winter-hardy (second category), quite drought tolerant (second category) species. Needs protection against wind over winter. The plants grow in deep rich soils. C. harringtonii can be used in group plantations in parks. The species is native to Japan, but sometimes is used in Western couuntires. Several forms are grown for this purpose. In Japan, $C$. harringtonii grows from Kyuschu in the south to Hokkaido in the north. Particularly, the species is found in Hondo in Chiba Prefecture on Kiyosumi Mountain located in Awa district of Awa province. It is also common in Nagasaki and Hiroshima Prefectures. The nana variety occurs in the eastern part of Honshu, and also Hokkaido, especially on coastal rocks and highland areas (Tripp, 1995). In Europe, C. harringtonii has been cultivated since 1829 . Many gardeners are familiar with this species named after Charles Harrington, the fourth duke Harrington, one of the first who grew the plant in a European garden in Elvaston. Omacetaxine, a substance obtained from the leaves of the plant is a new preparation aginst leukemia.
Pseudotsuga menziesii (Mirbel) Franco - Douglas fir is a tall coniferous tree from the Pinaceae family, which relates to the first and the second layers of forests. Also known as Douglas fir, Douglas pine, Oregon pine, and Columbian pine. Evergeen, phytoncidal, decorative fruit plant. Heliophyte, xeromesophyte, neutrophil, mesotrophic-eutrophic. Prefers acidic and neutral soils. Winter-hardy (second category), drought-tolerant (first category) plant. Grows better in well-drained, neutral loams. For greening it is used in parks, garden squares, embankments, more rarely in the streets. It is native to the western part of North America. Morphologically, P. menziesii is flexible, has many forms. P. menziesii var. menziesii forms a deeper root system. P. menziesii var. glauca manifests more flexibility, occurring in relic forests of British Columbia (Canada); in semi-arid vermouth steppe in the greater part of its range, forms the deepest roots. P. menziesii contains poriol flavanone (one of the flavonoids) produced in response to Poria weirii (Barton) infection. Different groups of Indians used bark, resin and needles of this plant for treating various diseases.

Chamaecyparis lawsoniana (A. Murray) Parl. is a tree of the second layer, belonging to the Curpessaceae family. Evergreen, phytoncidal, quite winter-hardy (second category) and drought-hardy (second category) plant. Mesophyte, but badly widstands air dryness, heliophyte, mesotrophic. The plant is not demanding in soil fertility requirements, but prefers light (light-loamy and sabulous) conditions. Ch. lawsoniana grows better in places sufficiently protected from wind and with good exposure to sunlight. It grows well in urban conditions; its blue-grey and blue forms are the most common. The species is characteristic for Oregon and North-West California. It grows at the height of $1,500 \mathrm{~m}$ above the sea level in the valleys of the Klamath Mountains, 
along streams. The species is very sensitive to infection by Phytophthora lateralis Tucker \& Milbrath.

Juniperus sabina L. or savin juniper, savin juniper of the Cupressaceae family is a dioecious, humifuse shrub $1.0-1.5 \mathrm{~m}$ high. It rapidly grows in width and forms dense thickets. More rarely, small trees $4 \mathrm{~m}$ in height with curved trunks are seen. The prostrate or shrub-like tree form occurs in many cities of Europe. Evergreen, phytoncidal, ground cover, soil protective, winter-hardy (first category) and drought-hardy (first category) species. Heliophyte, mesophyte, xeromesophyte. It is widely used for decorating rocky hills, slopes, in singular or group plantations on lawns or forest edges. Smoke and gas-resistant. Resilient in urban conditions, can be used for greening streets, except in industrial areas. Light-loving, undemanding in soil requirements, has soil-protecting abilities. Forests and groves of J. sabina are common in the steppe zone, on rocky mountain slopes and sandy dunes; sometimes the plant extends from the lower to the higher mountain belt $(1,000-2,300 \mathrm{~m}$ above the sea level), where it forms thickets. The range includes Asia Minor, the Caucasus, Russia (Urals, Siberia and Primorje), South-East Asia, South and Central Europe. J. sabina grows in very rare relic communities, and has a limited distribution, being at the verge of extinction (García-Cervigón et al., 2018; Lambevska-Hristova \& Bancheva, 2019). Shoots contain essential oil and are poisonous (San Feliciano et al., 1991; Batsatsashvili et al., 2017). Shoots and juniper berries contain glycosides, saponins, flavonids, tannins and up to $17 \%$ sabinol, which causes severe poisoning and miscarriages in cattle. Toxic properties of juniper sabina limit its application in therapeutic use. Most often, in folk medicine it is used as an external preparation. Ointment is rubed into the roots of hair in treatment of alopecia, applied to body areas affected by scabies, tincture is used against warts. Powder is sprinkled over pus ulcer. Essention from fresh branches with leaves is used in homeopathic treatment of diseases of the kidneys and the bladder, stranguria, gout, painful menstruations and impaired monthly cycle (Gubanov et al., 1976). The oils of this plant were dominated by $\alpha$-pinene, sabinene, and cedrol with moderate amounts of limonene, terpinen-4-ol, and elemol (Adams et al., 1998). Alongside some well-known compounds from acidic fraction of the extract of n-Hexane from leaves of J. sabina, San Feliciano et al. (1991) isolated two new lignans, derivative of naphthalene called junaphtoic acid and 3-O-demethylyatein. While studying phylogeographic peculiarities of $J$. sabina, Guo et al. (2010) presumed absence of regional interpopulational differentiation.

These species of plants remain poorly studied in relation to antimicrobial activity and can have a significant potential in human and veterinary medicine and. The objective of the article was determining the antibacterial effect of ethanol extracts of J. sabina, Ch. lawsoniana, $P$. menziesii and $C$. harringtonia on some species of microorganisms of the families Enterobacteriaceae, Staphylococcaceae, Yersiniaceae, Bacillaceae, Listeriaceae, Corynebacteriaceae, Campylobacteraceae, Nocardiaceae, Pseudomonadaceae and Saccharomycetaceae in vitro.

\section{Materials and methods}

Leaves and shoots of four species of coniferous plants were collected in the territory of Botanical Garden of Oles Honchar Dnipro National University (Khromykh et al., 2018; Boyko \& Brygadyrenko, 2019), dried at room temperature, cut, weighed and kept $24 \mathrm{~h}$ in $70 \%$ ethyl alcohol, filtrated. Antibacterial activity of the plant tinctures were identified using disk-diffusion in agar. Out of the $24 \mathrm{~h}$ culture of the ethanol strains of microorganisms of the family, a weighed amount was prepared according to the standard of turbidity of bacterial suspension equaling 0.5 units of density according to McFarland $(\mathrm{McF}) 1.5 \times 10^{8}$ CFU (colony-forming units), which was determined using a densitometer (Densimeter II). The obtained weighed amount was re-inoculated to Muller-Hinton agar (Himedia) followed by cultivation in a thermostat TSO-80/1 over $24 \mathrm{~h}$ at the temperature of $37^{\circ} \mathrm{C}$. On top of the re-inoculations, the disks saturated with tinctures of the extracted ethanol tinctures of the four species of plants were placed (Table 1).

\section{Table 1}

Used part of the four species of plants and the most important information on their antibacterial activity

\begin{tabular}{llcl}
\hline \multicolumn{1}{c}{ Family } & \multicolumn{1}{c}{ Species } & Used part of plant & The most important literature sources on the effect of the plant on bacteria \\
\hline Cupressaceae & Juniperus sabina L. & shoots & Elisoveckaya \& Brindza (2018), Zivić et al. (2019) \\
Cupressaceae & Chamaecyparis lawsoniana (A. Murray bis) Parl. & leaves & Smith et al. (2007), Kim et al. (2015), Palá-Paúl et al. (2015) \\
Pinaceae & Pseudotsuga menziesii (Mirb.) Franco & shoots & Takano et al. (2010), Dwivedi et al. (2015) \\
Taxaceae & Cephalotaxus harringtonii (Forbes) K. Koch & leaves & Watanabe \& Fukao (2009) \\
\hline
\end{tabular}

As a positive control we used disks with $15.0 \mu \mathrm{g}$ of azithromycin macrolid antibiotic of broad spectrum. Discs with $15.0 \mu \mathrm{g}$ amphotericinin were also used as a second control against Candida albicans. After $24 \mathrm{~h}$ growth of the culture was assessed using a multi-angle ruler for measuring growth inhibition zones in microorganisms (Antibiotic Zone Scale-C, model PW297, India) and the program TpsDig2 (2016, F. James Rohlf). The data in tables are presented as $\mathrm{x} \pm \mathrm{SD}$ (standard deviation).

\section{Results}

We observed inhibition of growth of separate strains of microorganisms exposed to ethanol extracts of the studied species of plants (Table 2). Extract from J. sabina moderately inhibited growth of E. coli ( 4.5 and $4.8 \mathrm{~mm}$, hereafter average radius of the growth inhibition zone is indicated in millimeters), E. faecalis (4.3), poorly inhibited growth of S. typhimurium (3.4), S. adobraco (2.7), P. vulgaris (2.8), P. mirabilis (2.1), Y. enterocolitica (2.5), S. marcescens (1.2), K. pneumoniae (2.5). Ethanol extract of $C h$. lawsoniana had more notable antibacterial action towards $E$. coli (8.8 and 9.3) and P. vulgaris (5.1), compared with $J$ sabina. Extract from P. menziesii was more efficient against $P$. mirabilis (10.5) compared with the three other plant preparations and the control. Ethanol extract of $C$. harringtonia had high inhibiting effect against strain of E. coli 055 (10.7), and also P. vulgaris (8.3) and S. marcescens (10.4). During the study on the effect of the preparations of plants against bacteria of the Staphylococcaceae family, we determined an intense antibacterial effect towards them demonstrated by ethanol extracts from C. harringtonia and J. sabina. We found significant inhi- biting effect of the extracts from J. sabina, Ch. lawsoniana and C. harringtonia on the microorganisms of the Bacillaceae family: $B$. cereus 14.2, 1.6 and 5.7, B. subtilis $-8.4,10.6$ and $0.0 \mathrm{~mm}$, respectively. We determined high sensitivity of $L$. ivanovi and $L$. monocytogenes to C. harringtonia (9.3 and 8.1), L. ivanovi to C. harringtonia (9.3), L. innocua to J. sabina and Ch. lawsoniana (12.4 and 10.6, respectively). Against $C$. xerosis, we observed growth inhibition zone of 6.4 and $6.8 \mathrm{~mm}$ produced by alcohol extracts of Ch. lawsoniana and P. menziesii and 10.6 and $9.7 \mathrm{~mm}$ by $J$. sabina and Ch. lawsoniana ( $9.3 \mathrm{~mm}$ during impact of azithromycin in the control). Bacteria of C. jejuni were highly susceptible only to ethanol extract of $C$. harringtonia (11.4). High antibacterial effect of the extracts from J. sabina, Ch. lawsoniana and P. menziesii was exerted against Rhodococcus equi (27.5, 14.3 and 8.7) during moderate exposure to ethanol extract of $C$. harringtonia (4.4). Bacteria of $P$. aeruginosa were highly sensitive to ethanol extract from J. sabina (10.5), moderately sensitive to Ch. lawsoniana $(6.4 \mathrm{~mm})$. We should note antibiotic resistance of the studied strains of $L$. monocytogenes, $C$. jejuni, $P$. vulgaris, $P$. mirabilis, $P$. aeruginosa, $K$. pneumoniae and $S$. marcescens to azithromycin. Extract from $C$. harringtonia exerted high inhibiting action towards C. albicans (9.8). Compared to amphotericin, higher growth inhibition zones were also produced by ethanol extracts from $C h$. lawsoniana and $P$. menziesii (3.7 and $3.4 \mathrm{~mm}$, respectively).

\section{Discussion}

Research has been conducted on species of gymnosperm plants, which apart from antibacterial and antifungicidial activity are also charac- 
terized by cytostatic properties against different types of the tumour tissues. Shokrzadeh et al. (2009), Janar et al. (2012) and Huyan et al. (2016) noted moderate inhibiting activity of diterpenoids of J. sabina towards five species of human tumour cells. Zhao et al. (2015) determined anti-inflammatory effect of shoots and leaves of $J$. sabina due to flavone glycoside isoscutellarein 7-O- $\beta$-D- rhamnopyranosyl $-(1 \rightarrow 3)-\alpha-\mathrm{L}-$ xylopyranoside. Analgesic and anti-inflammatory effects of general flavanoids from leaves of $J$. sabina have been proven on rodents (Zhao et al., 2018). Abdel-Kader et al. (2019) determined the hepatoprotective activity of $J$. sabina, which was assessed by biochemical parameters of blood serum of rats, such as aspartate-aminotransferase (AST), alanine aminotrasferase (ALT), gamma-glutamyl transpeptidase (GGT), alkaline phosphatase (ALP) and total bilirubin. Khani et al. (2017) and Elisoveckaya \& Brindza (2018) determined that essential oil from J. sabina has insecticidal, antifeedant, deterrent and repellent properties. Results of the studies by Živić et al. (2019) and Semerdjieva et al. (2019) allow one to state that ethanol extract of J. communis has a high antioxidant activity due to the content of total phenol compounds and total amount of flavonoids.

Table 2

Width of the growth inhibition zone (mm) demonstrated by the extracts from Juniperus sabina, Chamaecyparis lawsoniana, Pseudotsuga menziesii and Cephalotaxus harringtonia against 24 strains of microorganisms $(\mathrm{n}=12)$

\begin{tabular}{|c|c|c|c|c|c|}
\hline Strains of microorganisms & Juniperus sabina & Chamaecyparis lawsoniana & Pseudotsuga menziesii & Cephalotaxus harringtonia & Control $^{*}$ \\
\hline Enterococcus faecalis ATCC 19433 & $4.3 \pm 0.65$ & $0 \pm 0$ & $1.1 \pm 0.23$ & $0 \pm 0$ & $23.9 \pm 2.45$ \\
\hline Enterobacter aerogenes ATCC 10006 & $0 \pm 0$ & $0 \pm 0$ & $0 \pm 0$ & $0 \pm 0$ & $15.9 \pm 1.67$ \\
\hline Escherichia coli F50 & $4.8 \pm 0.35$ & $8.8 \pm 0.67$ & $4.3 \pm 0.34$ & $2.7 \pm 0.21$ & $17.8 \pm 1.87$ \\
\hline E. coli 055 & $4.5 \pm 0.34$ & $9.3 \pm 0.56$ & $3.7 \pm 0.42$ & $10.7 \pm 1.45$ & $15.6 \pm 1.62$ \\
\hline Staphylococcus aureus ATCC 25923 & $11.5 \pm 0.64$ & $4.4 \pm 0.32$ & $4.1 \pm 0.33$ & $21.2 \pm 2.41$ & $21.6 \pm 2.45$ \\
\hline S. epidermidis ATCC 14990 & $0 \pm 0$ & $0 \pm 0$ & $0 \pm 0$ & $13.4 \pm 1.45$ & $10.3 \pm 1.34$ \\
\hline Bacillus subtilis ATCC 6633 & $8.4 \pm 1.12$ & $10.6 \pm 1.55$ & $0 \pm 0$ & $0 \pm 0$ & $30.3 \pm 3.05$ \\
\hline B. cereus ATCC 10702 & $14.2 \pm 1.87$ & $1.6 \pm 0.32$ & $0 \pm 0$ & $5.7 \pm 0.77$ & $16.8 \pm 1.86$ \\
\hline Listeria ivanovi & $2.3 \pm 0.43$ & $0 \pm 0$ & $0 \pm 0$ & $9.3 \pm 0.76$ & $14.7 \pm 1.21$ \\
\hline L. iпnосиа АТСС 33090 & $12.4 \pm 1.55$ & $10.6 \pm 1.18$ & $0 \pm 0$ & $0 \pm 0$ & $25.1 \pm 1.98$ \\
\hline L. monocytogenes ATCC 19112 & $0 \pm 0$ & $0 \pm 0$ & $0 \pm 0$ & $8.1 \pm 0.87$ & $0 \pm 0$ \\
\hline Corynebacterium xerosis 1911 & $10.6 \pm 0.56$ & $6.4 \pm 0.43$ & $6.8 \pm 0.57$ & $9.7 \pm 0.89$ & $9.3 \pm 1.34$ \\
\hline Campylobacter jejuni ATCC 11322 & $0 \pm 0$ & $0 \pm 0$ & $0 \pm 0$ & $11.4 \pm 1.12$ & $0 \pm 0$ \\
\hline Rhodococcus equi ATCC 6939 & $27.5 \pm 2.89$ & $14.3 \pm 1.54$ & $8.7 \pm 0.83$ & $4.4 \pm 0.42$ & $19.1 \pm 1.98$ \\
\hline Proteus vulgaris ATCC 13315 & $2.8 \pm 0.54$ & $5.1 \pm 0.43$ & $0 \pm 0$ & $8.3 \pm 0.87$ & $0 \pm 0$ \\
\hline P. mirabilis ATCC 14153 & $2.1 \pm 0.23$ & $0 \pm 0$ & $10.5 \pm 0.93$ & $0 \pm 0$ & $0 \pm 0$ \\
\hline Salmonella typhimurium ATCC 14028 & $3.4 \pm 0.21$ & $2.2 \pm 0.13$ & $1.9 \pm 0.13$ & $0 \pm 0$ & $20.3 \pm 1.54$ \\
\hline S. adobraco 1 & $2.7 \pm 0.19$ & $2.7 \pm 0.39$ & $1.4 \pm 0.12$ & $0 \pm 0$ & $26.3 \pm 2.76$ \\
\hline Pseudomonas aeruginosa ATCC 2353 & $10.5 \pm 0.98$ & $0 \pm 0$ & $0 \pm 0$ & $0 \pm 0$ & $0 \pm 0$ \\
\hline P. aeruginosa ATCC 2799 & $0 \pm 0$ & $6.4 \pm 0.78$ & $0 \pm 0$ & $0 \pm 0$ & $0 \pm 0$ \\
\hline Klebsiella pneumoniae ATCC 13883 & $2.5 \pm 0.21$ & $1.7 \pm 0.12$ & $0 \pm 0$ & $0 \pm 0$ & $0 \pm 0$ \\
\hline Yersinia enterocolitica ATCC 9610 & $2.5 \pm 0.22$ & $0 \pm 0$ & $0 \pm 0$ & $0 \pm 0$ & $12.8 \pm 1.27$ \\
\hline Serratia marcescens ATCC 8100 & $1.2 \pm 0.23$ & $0 \pm 0$ & $2.8 \pm 0.23$ & $10.4 \pm 0.94$ & $0 \pm 0$ \\
\hline Candida albicans ATCC 2091 & $2.2 \pm 0.41$ & $3.7 \pm 0.34$ & $3.4 \pm 0.31$ & $9.8 \pm 0.92$ & $\begin{array}{c}0 \pm 0^{*} \\
2.4 \pm 0.21^{* *}\end{array}$ \\
\hline
\end{tabular}

Note: $*$ - discs with $15.0 \mu \mathrm{g}$ of azithromycin were used for all bacteria as positive control; ** - discs with $15.0 \mu \mathrm{g}$ amphotericinin were used as positive control for Candida albicans (Valle et al., 2015).

Palá-Paúl et al. (2015) researched Ch. lawsoniana. They showed that the essential oils from young shoots and leaves of Ch. lawsoniana exert high antibacterial and antifungicidal activity towards Candida albicans, Bacillus subtilis, Staphylococcus aureus and Micrococcus luteus: essential oil was more effective against gram-positive rather than gram-negative bacteria. Recently, interest has developed to the use of essential oils from shoots of Ch. lawsoniana in commercial products, such as preparations against pests and cosmetics (Duringer et al., 2015). To assess the relative toxicological risk from these oils for fresh-water and marine organisms, acute aquatic toxicity of these oils was assessed using the planktonic crustacean Daphnia magna Straus, rainbow trout Oncorhynchus mykiss (Walbaum) and microalga Raphidocelis subcapitata (Korshikov) Nygaard, Komárek, J. Kristiansen \& O. M. Skulberg. For the oils from leaves of Ch. lawsoniana, toxicity against $D$. magna or O. mykiss was not observed even in $5.0 \mathrm{mg} / \mathrm{L}$ (the highest tested concentration and the threshold of solubility). Research on toxicity against $R$. subcapitata using density of cells of algae showed that the value of $\mathrm{EC}_{50}$ over 72 and $96 \mathrm{~h}$ equaled $1.7 \mathrm{mg} / \mathrm{L}$, and the concentration without observed effect (NOEC) was $0.63 \mathrm{mg} / \mathrm{L}$. Forty-eight $\mathrm{h} \mathrm{EC}_{50}$ for D. magna equaled $1.9 \mathrm{mg} / \mathrm{L}$; value of NOEC for density of the cells of algae equaled $1.25(72 \mathrm{~h})$ and $0.63 \mathrm{mg} / \mathrm{L}(96 \mathrm{~h})$. The emergence of antibiotic-resistant bacteria has caused difficulties in the treatment of infectious diseases (Kim et al., 2015). Methicillin-resistant Staphylococcus aureus is one of the commonest recognized antibiotic-resistant bacteria. New antibiotics for the treatment of MRSA in humans are urgently needed. Raw materials obtained from natural sources can be used for the development of new antibiotics, for example Chamaecyparis obtusa (Siebold \& Zucc.) Endl., which is traditionally used for treating asthma. Kim et al. (2015) studied antibacterial activity of essential oil from leaves of Ch. obtusa against MRSA. Growth of MRSA and production of acid during metabolism of glucose was inhibited in Staphylococcus by the concentration of $0.1 \mathrm{mg} / \mathrm{mL}$ of Ch. obtusa. Smith et al. (2007) showed that within the framework of a project aimed at characterizing the antibacterial or immune-modulating activity of compounds of immature conifer cones against multi-drug resistance (MDR) strains of $S$. aureus, eight compounds were extracted from Ch. lawsoniana. Active compounds are mostly diterpenes with minimum inhibitory concentrations equaling 4-128 $\mu \mathrm{g} / \mathrm{mL}$ against strains of $S$. aureus which are resistant to methicillin (EMRSA). Out of Ch. lawsoniana, diterpene ferruginol, pisiferol and its epimer 5-epipisiferol, formazan oxide, transcommunic acid and torulosal, sesquiterpenic oplopanonil acetate and germacrane $4 \beta$-hydroxigermacra-1(10)-5-dien were obtained. Some of these compounds also exerted modulating activity in potentiation of antibiotic activity against efflux strains, and ferruginol used in sub-inhibiting concentration caused 80-fold increase in the activity of oxacillin against strain of EMRSA-15. Yang et al. (2007) determined that essential oil from leaves of Ch. obtusa has relatively strong antibacterial activity against gram-positive bacteria and some fungi.

Massicotte et al. (1992) determined that tubers on the roots of $P$. menziesii are present as ectomycorrhizal formations. Spectroscopy showed that the crystals found in the zone of loose hyphae of fungi perhaps contain calcium oxalate. Bacteria locate either in the hyphae of fungi in the bark of roots, or as colonies on the surface. These results allow us to assume that the roots of plants can be a valuable resource, because they contain a large amount of anti-fungi and allelopathc compounds (Massicotte et al., 1992).

Palá-Paúl et al. (2015) report new data on antibacterial and antifungal activity of essential oil from Ch. lawsoniana. Leaves of juniper are practically safe for aquatic organisms (Duringer et al., 2015). Cedar oil did not exhibit toxicity against Oncorhynchus mykiss (Walbaum) or 
Selenastrum capricornutum Printz even in $0.5 \mathrm{mg} / \mathrm{L}$ (the highest tested concentration and threshold of solubility). Kim (2015) determined formation of biofilm of MRSA using a scanning microscopy and staining with c safranin. Chamaecyparis obtusa (Siebold \& Zucc.) Endl. Inhibited the formation of biofilm of MRSA in concentrations of over $0.1 \mathrm{mg} / \mathrm{mL}$. These data indicate that Ch. obtusa has antibacterial effect against MRSA, which could be associated with such components of the plant tissues as sabinene (19.1\%), $\alpha$-terpinyl acetate (17.0\%), bornyl acetate $(10.5 \%)$, limonene $(8.5 \%)$, elemol $(7.5 \%)$, myrcene $(5.9 \%), \gamma$ terpinene (4,0\%) and hibaene (3.0\%). Lee (2009) and Morikawa et al. (2012) studied the bioactivity of extracts of the pith of a branch of Ch. obtusa and compared it to the extracts from the pith of the trunk: antifungal activity was studied towards four species of fungi (Trametes versicolor (L.) Lloyd, Fomitopsis palustris (Berk. \& M. A. Curtis) Gilb. \& Ryvarden, Trichoderma virens (J. H. Mill. et al.) Arx and Rhizopus oryzae Went \& H. C. Prinsen Geerligs) and antagonistic activity against aquatic crustaceans Artemia salina (L.).

Watanabe \& Fukao (2009) determined that $C$. harringtonia exerted a broad anti-tumour activity in rodents and anti-leukemia effect in people. They discovered that the substances from the plants are metabolized to the acidic product HHT-acid (2'-hydroxy-2'-( $\alpha$-acetic acid)-6'hydroxy-6'-methylheptanoil cephalotaxine) during in vitro incubation with human or mice blood plasma. Concentration of HHT which inhibited by $50 \%$ growth of human leukemia cells HL-60 was $20 \mathrm{ng} / \mathrm{mL}$, whereas for HHT-acid it equaled 14,500 ng/mL (acidic form was more than 700 times less cytotoxic than HHT). $\mathrm{LD}_{50}$ for HHT equaled $6.7 \mathrm{mg} / \mathrm{kg}$, at the same time HHT-acid exhibited no notable toxic effects even in the doses of $280 \mathrm{mg} / \mathrm{kg}$.

Extract from immature fruits of $C$. harringtonia is most efficient in inhibiting the growth of Bacillus cereus and Leuconostoc mesenteroides (Tsenkovskii) van Tieghem, its antibacterial activity was tested against 22 species of gram-positive, 7 species of gram-negative bacteria and 13 species of fungi. Extract from $C$. harringtonia exerted antibacterial activity towards gram-positive bacteria with minimum inhibiting concentrations (MIC) of $25-200 \mu \mathrm{g} / \mathrm{mL}$ in agar broth and $5-40 \mu \mathrm{g} / \mathrm{mL}$ in liquid broth, antimicrobial effect was higher in acidic and alkaline media than in neutral conditions (Watanabe \& Fukao, 2009).

From leaves of $C$. harringtonia f. fastigiata, Morita et al. (2000, 2010) a new alkaloid cephastigiamide A was extracted and its structure was studied using two-dimensional NMR spectroscopy and chemical degradation. Harringtonin, desoxyharringtonin and homodesoxyharringtonin demonstrated notable antiplasmatic action towards Plasmodium falciparum Welch, but not towards Leishmania major Yakimoff et Schokhor. Six new alkaloids (cephalezomines A-F) were isolated together with ten already known alkaloids from leaves of $C$. harringtonia var. nana; cephalezomines A-F displayed potent cytotoxicity against tumour cells (Morita et al., 2010, 2012).

Takano et al. (2010) and Dwivedi et al. (2015) focused on infections associated with biomaterials. Microbial adhesion on implants caused formation of biofilm, which ultimately led to damage to the implants. Therefore, for effective treatment against biofilms of $S$. aureus, which are responsible for most infections associated with biomaterials, these authors propose using silver nanoparticles and extracts from leaves of Pseudotsuga menziesii.

From seeds of $C$. harringtonia, Politi et al. (2003) extracted six diterpenoids (8$\beta$-hydroxi-9(11),13- abietadien -12-one and 5,6-didehydroferruginol, ferruginol, sugiol, 6,12-dihydroxiabieta-5,8,11,13-tetraene7-one and abieta-8,11,13-trien-7 $\beta$-ol). They conducted in vitro studies on these compounds against clinically isolated bacteria and strains of Candida. Ferruginol and 6,12-dihydroxiabieta-5,8,11,13-tetraene-7-one exerted antimicrobial activity against several gram-positive bacteria. None of the six diterpenes was active against gram-negative organisms and tested species of yeasts.

Evanno et al. (2008) observed significant antifungal activity of harringtonolide - a complex polycyclic condensed norditerpene extracted from C. harringtonia var. drupacea. Ram \& Kumari (2001) also confirmed anti-tumour activity of $C$. harringtonia.

Smith et al. (2008) extracted a new abietan diterpene, from the bark of the stem of Prumnopitys andina (Poepp. ex Endl.) de Laub. This new com- pound presented antibacterial activity in $8 \mu \mathrm{g} / \mathrm{mL}$ against two strains of S. aureus, but, it is interesting that it was not active in $128 \mu \mathrm{g} / \mathrm{mL}$ against a strain of wild-type and Methicillin-resistant $S$. aureus. Smith et al. (2008) note that ferruginol was active against these four strains of S. aureus. Presence of acetoxy group caused harmful effect on the antibacterial activity towards certain strains.

The antibacterial in vitro effect which we observed from J. sabina exceeded a $8 \mathrm{~mm}$ wide zone of inhibition of growth of 7 species of bacteria (S. aureus, B subtilis, B. cereus, L. innocua, C. xerosis, Rh. equi and $P$. aeruginosa), $C$. lawsoniana had the same effect against 5 species (E. coli, B. subtilis, L. innocua and Rh. equi), P. menziesii - only against 2 species (Rh. equi and P. mirabilis) and C. harringtoniaagainst 10 species of microorganisms (E. coli, S. aureus, S. epidermidis, L. ivanovi, L. monocytogenes, C. xerosis, C. jejuni, P. vulgaris, S. marcescens and $C$. albicans). Further detailed study of individual chemical substances present in those plants should be undertaken in both in vitro and in vivo experiments.

\section{Conclusion}

None of the four species of gymnosperms produced notable (growth inhibition zone of over $8 \mathrm{~mm}$ ) effect towards E. faecalis, E. aerogenes, S. typhimurium, S. adobraco, K. pneumoniae and Y. enterocolitica. Negative effect (growth inhibition zone of over $8 \mathrm{~mm}$ ) on $E$. coli was exerted by alcohol extracts of Ch. lawsoniana and C. harringtonia, extracts of $J$. sabina and C. harringtonia took effect on S. aureus, only $C$. harringtonia affected $S$. epidermidis, against $B$. subtilis $-J$. sabina and Ch. lawsoniana were effective, against $B$. cereus - only $J$. sabina, against $L$. ivanovi - only $C$. harringtonia, against $L$. innocua - J. sabina and Ch. lawsoniana, against $L$. monocytogenes - only $C$. harringtonia, against $C$. xerosis $-J$. sabina and $C$. harringtonia, against $C$. jejunionly $C$. harringtonia, against $R h$. equi - J. sabina, Ch. lawsoniana and $P$. menziesii, against $P$. vulgaris - only $C$. harringtonia, against $P$. mirabilis - only $P$. menziesii, against $P$. aeruginosa - only $J$. sabina, against $S$. marcescens - only $C$. harringtonia, and against $C$. albicans only alcohol extract of $C$. harringtonia had negative effect. We consider that it is practical to recommend ethanol extracts from J. sabina, Ch. lawsoniana, $P$. menziesii and $C$. harringtonia, or individual compounds present in them, to be used in further studies on treatment against polyresistant strains of the abovementioned microorganisms.

\section{References}

Abdel-Kader, M. S., Hamad, A. M., Alanazi, M. T., Alanazi, A. H., Ali, R., Foudah, A. I., \& Alqarni, M. H. (2019). Characterization and hepatoprotective evaluation of sesquiterpenes and diterpenes from the aerial parts of Juniperus sabina L. Saudi Pharmaceutical Journal, 27(7), 920-929.

Adams, R. P., Dembitsky, A. D., \& Shatar, S. (1998). The leaf essential oils and taxonomy of Juniperus centrasiatica Kom., J. jarkendensis Kom., J. pseudosabina Fisch., Mey. \& Ave-Lall., J. sabina L. and J. turkestanica Kom. from Central Asia. Journal of Essential Oil Research, 10(5), 489-496.

Barton, G. M. (1972). New C-methylflavanones from Douglas-fir. Phytochemistry, 11(1), 426-429.

Batsatsashvili, K., Mehdiyeva, N. P., Kikvidze, Z., Khutsishvili, M., Maisaia, I., Sikharulidze, S., Tchelidze, D., Alizade, V. M., Zambrana, N. Y. P., \& Bussmann, R. W. (2017). Juniperus communis L., Juniperus sabina L., Cupressaceae. Ethnobotany of the Caucasus, 369-373.

Boyko, O. O., \& Brygadyrenko, V. V. (2019). Nematocidial activity of aqueous solutions of plants of the families Cupressaceae, Rosaceae, Asteraceae, Fabaceae, Cannabaceae and Apiaceae. Biosystems Diversity, 27(3), 227-232.

Boyko, O. O., Zazharska, N. M., \& Brygadyrenko, V. V. (2016). The influence of the extent of infestation by helminths upon changes in body weight of sheep in Ukraine. Visnyk of Dnipropetrovsk University, Biology, Ecology, 24(1), 3-7.

Duringer, J. M., Swan, L. R., Walker, D. B., \& Craig, A. M. (2009). Acute aquatic toxicity of western juniper (Juniperus occidentalis) foliage and Port Orford cedar (Chamaecyparis lawsoniana) heartwood oils. Environmental Monitoring and Assessment, 170(1-4), 585-598.

Dwivedi, P., Narvi, S. S., \& Tewari, R. P. (2015). Coating made from Pseudotsuga menziesii phytosynthesized silver nanoparticles is efficient against Staphylococcus aureus biofilm formation. Nano Life, 5(4), 1540006.

Evanno, L., Jossang, A., Nguyen-Pouplin, J., Delaroche, D., Herson, P., Seuleiman, M., Bodo, B., \& Nay, B. (2008). Further studies of the norditerpene (+)- 
harringtonolide isolated from Cephalotaxus harringtonia var. drupacea: Absolute configuration, cytotoxic and antifungal activities. Planta Medica, 74(8), $870-872$.

Farjon, A. (2013). Juniperus sabina var. sabina. The IUCN Red List of Threatened Species, 2013, e.T191611A1991189.

García-Cervigón, A. I., Linares, J. C., García-Hidalgo, M., Camarero, J. J., \& Olano, J. M. (2018). Growth delay by winter precipitation could hinder Juniperus sabina persistence under increasing summer drought. Dendrochronologia, 51, 22-31.

Gubanov, I. A., Krylova, I. L., \& Tihonova, V. L. (1976). Dikorastushhie poleznye rastenija SSSR [Wild useful plants of the USSR]. Mysl', Moscow (in Russian).

Guo, Y.-P., Zhang, R., Chen, C.-Y., Zhou, D.-W., \& Liu, J.-Q. (2010). Allopatric divergence and regional range expansion of Juniperus sabina in China. Journal of Systematics and Evolution, 48(3), 153-160.

Huyan, T., Li, Q., Wang, Y.-L., Li, J., Zhang, J.-Y., Liu, Y.-X., Shahid, M. R., Yang, H., \& Li, H.-Q. (2016). Anti-tumor effect of hot aqueous extracts from Sonchus oleraceus (L.) L. and Juniperus sabina L. - two traditional medicinal plants in China. Journal of Ethnopharmacology, 185, 289-299.

Janar, J., Nugroho, A. E., Wong, C. P., Hirasawa, Y., Kaneda, T., Shirota, O., \& Morita, H. (2012). Sabiperones A-F, new diterpenoids from Juniperus sabina. Chemical and Pharmaceutical Bulletin, 60(1), 154-159.

Khani, A., Rashid, B., \& Mirshekar, A. (2017). Chemical composition and insecticidal efficacy of Juniperus polycarpus and Juniperus sabina essential oils against Tribolium confusum (Coleoptera: Tenebrionidae). International Journal of Food Properties, 20, 1221-1229.

Khromykh, N., Lykholat, Y., Shupranova, L., Kabar, A., Didur, O., Lykholat, T., \& Kulbachko, Y. (2018). Interspecific differences of antioxidant ability of introduced Chaenomeles species with respect to adaptation to the steppe zone conditions. Biosystems Diversity, 26(2), 132-138.

Kim, E.-S., Kang, S.-Y., Kim, Y.-H., Lee, Y.-E., Choi, N.-Y., You, Y.-O., \& Kim, K.-J. (2015). Chamaecyparis obtusa essential oil inhibits methicillin-resistant Staphylococcus aureus biofilm formation and expression of virulence factors. Journal of Medicinal Food, 18(7), 810-817.

Lambevska-Hristova, A., \& Bancheva, S. (2019). Overview of the population state of savin juniper (Juniperus sabina) in the Rila Mt. ARPHA Conference Abstracts, 2, e46499.

Lee, J.-H. (2009). Comparison of chemical compositions and antimicrobial activities of essential oils from three conifer trees: Pinus densiflora, Cryptomeria japonica, and Chamaecyparis obtusa. Journal of Microbiology and Biotechnology, 19(4), 391-396.

Maltas, E., Vural, H. C., \& Yildiz, S. (2011). Antioxidant activity and fatty acid composition of Ginkgo biloba from Turkey. Journal of Food Biochemistry, 35(3), 803-818.

Massicotte, H. B., Melville, L. H., Li, C. Y., \& Peterson, R. L. (1992). Structural aspects of Douglas-fir (Pseudotsuga menziesii (Mirb.) Franco) tuberculate ectomycorrhizae. Trees, 6(3) 137-146.

Moirangthem, D. S., Borah, J. C., Laishram, S., Kalita, M. C., \& Talukdar, N. C. (2014). HPLC analysis of harringtonine and homoharringtonine in the needles of Cephalotaxus griffithii alkaloid fraction and cytotoxic activity on chronic myelogenous leukaemia K562 cell. Natural Product Research, 28(18), 1503-1506.

Morikawa, T., Ashitani, T., Sekine, N., Kusumoto, N., \& Takahashi, K. (2012). Bioactivities of extracts from Chamaecyparis obtusa branch heartwood. Journal of Wood Science, 58(6), 544-549.

Morita, H., Arisaka, M., Yoshida, N., \& Kobayashi, J. (2000). Cephalezomines A-F, potent cytotoxic alkaloids from Cephalotaxus harringtonia var. nana. Tetrahedron, 56(19), 2929-2934.

Morita, H., Nagakura, Y., Hosoya, T., Ekasari, W., Widyawaruyanti, A., MoriYasumoto, K., Sekita, S., \& Hirasawa, Y. (2010). Cephastigiamide A, and antiplasmodial activity of Cephalotaxus alkaloids from Cephalotaxus harringtonia forma fastigiata. Heterocycles, 81(2), 441-450.

Palá-Paúl, J., Usano-Alemany, J., Granda, E., \& Soria, A.-C. (2012). Antifungal and antibacterial activity of the essential oil of Chamaecyparis lawsoniana from Spain. Natural Product Communications, 7(10), 1383-1386.
Palchykov, V. A., Zazharskyi, V. V., Brygadyrenko, V. V., Davydenko, P. O., Kulishenko, O. M., Borovik, I. V., Chumak, V., Kryvaya, A., \& Boyko, O. O. (2019). Bactericidal, protistocidal, nematodicidal properties and chemical composition of ethanol extract of Punica granatum peel. Biosystems Diversity, 27(3), 300-306.

Palchykov, V. A., Zazharskyi, V. V., Brygadyrenko, V. V., Davydenko, P. O., Kulishenko, O. M., \& Borovik, I. V. (2020). Chemical composition and antibacterial effect of ethanolic extract of Buxus sempervirens on cryogenic strains of microorganisms in vitro. Chemical Data Collections, 25, 100323.

Politi, M., Braca, A., De Tommasi, N., Morelli, I., Manunta, A., Battinelli, L., \& Mazzanti, G. (2003). Antimicrobial diterpenes from the seeds of Cephalotaxus harringtonia var. drupacea. Planta Medica, 69(5), 468-470.

Ram, V. J., \& Kumari, S. (2001). Natural products of plant origin as anticancer agents. Drug News and Perspectives, 14(8), 465-482.

San Feliciano, A., Miguel del Corral, J. M., Gordaliza, M., \& Castro, M. A. (1991). Two diterpenoids from leaves of Juniperus sabina. Phytochemistry, 30(2), 695-697.

San Feliciano, A., Miguel Del Corral, J. M., Gordaliza, M., \& Castro, A. (1991). Acidic and phenolic lignans from Juniperus sabina. Phytochemistry, 30(10), 3483-3485.

Semerdjieva, I. B., Shiwakoti, S., L. Cantrell, C., D. Zheljazkov, V., Astatkie, T., Schlegel, V., \& Radoukova, T. (2019). Hydrodistillation extraction kinetics regression models for essential oil yield and composition in Juniperus virginiana, J. excelsa, and J. sabina. Molecules, 24(5), 986.

Shokrzadeh, M., Azadbakht, M., Ahangar, N., Naderi, H., \& Saeedi Saravi, S. (2009). Cytotoxic effects of hydroalcoholic extract of Juniperus sabina compared with hydroalcoholic extract of Taxus baccata and cisplatin on normal and cancer cell lines. Planta Medica, 75(9), 1077.

Smith, E. C. J., Wareham, N., Zloh, M., \& Gibbons, S. (2008). 2ß-Acetoxyferruginol - a new antibacterial abietane diterpene from the bark of Prumnopitys andina. Phytochemistry Letters, 1(1), 49-53.

Smith, E. C. J., Williamson, E. M., Wareham, N., Kaatz, G. W., \& Gibbons, S. (2007). Antibacterials and modulators of bacterial resistance from the immature cones of Chamaecyparis lawsoniana. Phytochemistry, 68(2), 210-217.

Takano, I., Yasuda, I., Nishijima, M., Hitotsuyanagi, Y., Takeya, K., \& Itokawa, H. (1996). Drupangtonine, a novel antileukemic alkaloid from Cephalotaxus harringtonia var. drupacea. Bioorganic and Medicinal Chemistry Letters, 6(14), 1689-1690.

Tripp, K. E. (1995). Cephalotaxus: The plum yews. Arnoldia, 55(1), 24-39.

Watanabe, K., \& Fukao, T. (2009). Antibacterial effects of unripe Cephalotaxus harringtonia fruit extract on gram-positive bacteria. Nippon Shokuhin Kagaku Kogaku Kaishi, 56(10), 533-540.

Yang, J.-K., Choi, M.-S., Seo, W.-T., Rinker, D. L., Han, S. W., \& Cheong, G.W. (2007). Chemical composition and antimicrobial activity of Chamaecyparis obtusa leaf essential oil. Fitoterapia, 78(2), 149-152.

Zazharskyi, V. V., Davydenko, P. O., Kulishenko, O. M., Borovik, I. V., \& Brygadyrenko, V. V. (2019a). Antimicrobial activity of 50 plant extracts. Biosystems Diversity, 27(2), 163-169.

Zazharskyi, V., Davydenko, P., Kulishenko, O., Borovik, I., Brygadyrenko, V., \& Zazharska, N. (2019b). Antibacterial activity of herbal infusions against Staphylococcus aureus, Staphylococcus epidermidis and Pseudomonas aeruginosa in vitro. Magyar Állatorvosok Lapja, 141, 693-704.

Zhao, J., Maitituersun, A., Li, C., Li, Q., Xu, F., \& Liu, T. (2018). Evaluation on analgesic and anti-inflammatory activities of total flavonoids from Juniperus sabina. Evidence-Based Complementary and Alternative Medicine, 2018, article ID 7965306.

Zhao, J., Xu, F., Ji, T., Xu, F., \& Li, C. (2015). A new flavone glycoside from twigs and leaves of Juniperus sabina. Chemistry of Natural Compounds, 51(3), 448-450.

Živić, N., Milošević, S., Dekić, V., Dekić, B., Ristić, N., Ristić, M., \& Sretić, L. (2019). Phytochemical and antioxidant screening of some extracts of Juniperus communis L. and Juniperus oxycedrus L. Czech Journal of Food Sciences, 37(5), 351-358. 